\title{
Optimization of fourteen microsatellite loci in a Mediterranean demosponge subjected to population decimation, Ircinia fasciculata
}

\author{
Ana Riesgo', Gema Blasco¹, Patrick M. Erwin², Rocío Pérez-Portela³, Susanna López- \\ Legentil $1^{1,2}$
}

${ }^{1}$ Department of Animal Biology, University of Barcelona, Barcelona, Spain

${ }^{2}$ Department of Biology and Marine Biology, Center for Marine Science, University of North Carolina Wilmington, USA

${ }^{3}$ Center for Advanced Studies of Blanes (CEAB-CSIC), Girona, Spain

\begin{abstract}
The recovery potential of decimated populations of sponges will largely hinge on their populations' size retrieval and their connectivity with conspecifics in unaffected locations. Here, we report on the development of microsatellite markers for estimation of the population connectivity and bottleneck and inbreeding signals in a Mediterranean sponge suffering from disease outbreaks, Ircinia fasciculata. From the 220,876 sequences obtained by genomic pyrosequencing, we isolated 14 polymorphic microsatellite loci and assessed the allelic variation of loci in 24 individuals from two populations in the Northwestern Mediterranean. The allele number per locus ranged from three to 11 , observed heterozygosity from $0.68-0.73$, and expected heterozygosity from $0.667-0.68$. No significant linkage disequilibrium between pairs of loci was detected. The fourteen markers developed here will be valuable tools for conservation strategies across the distributional range of this species allowing the detection of populations with large genetic diversity loss and high levels of inbreeding.
\end{abstract}

\section{INTRODUCTION}

Sponges play an ecologically important role given their abundance and diversity as well as their contribution to primary production and nitrification through complex symbioses in marine benthic communities (Hentschel et al. 2002; Webster 2007). Despite the large number of antibiotics compounds isolated from marine sponges (Avila et al. 2008), they are still 
subjected to numerous diseases caused by bacteria (Webster 2007). In the Mediterranean, periodic episodes of massive die-offs have been reported for the genus Ircinia (e.g., Maldonado et al. 2010; Cebrian et al. 2011). In these cases, environmental stress due to elevated seawater temperatures has been suggested to trigger the disease (Maldonado et al. 2010: Cebrián et al. 2011) by increasing the prevalence and virulence of pathogens (Sutherland et al. 2004).

Massive mortalities are drastically reducing population size and creating extensive gaps in the distribution of many species, including sponges. Molecular markers have been widely applied in conservation biology to evaluate the vulnerability of marine species (e.g., Hellberg et al. 2002) but studies on population genetics using microsatellite markers are available for very few sponges (see Pérez-Portela et al. 2013). Here, we report on the optimization of microsatellite markers further estimation of genetic diversity indexes, populations' connectivity, and for detecting signals of recent bottlenecks in order to evaluate the degree of vulnerability of the sponge Ircinia fasciculata from the Mediterranean.

\section{Material and Methods}

Prior to DNA extraction, sponge tissue was dissociated and the bacterial symbionts removed by sequential centrifugations. Genomic DNA was extracted using DNeasy Tissue and Blood extraction kit (QIAGEN) to a final DNA concentration of $2 \mu \mathrm{g}$ and distributed in two lanes of a plate. Pyrosequencing was performed on a Roche Life Science 454 GS-FLX System at the Scientific-Technical Services of the University of Barcelona. Sequences $(220,876)$ were searched for perfect microsatellites (di-, tri-, tetra- and pentanucleotides) with at least eight repeats and enough priming regions with Phobos (http://www.rub.de/spezzoo/cm/cm_phobos.htm). 49,109 sequences contained microsatellites (Table 1). Thirty-six primer sets were designed with the software PRIMER 3 (Table 2).

Amplification success and polymorphism were tested in two populations of the NW Mediterranean (Costa Brava) collected in 2010-2012: Els Caials (42¹7'19'N 3¹6'40'E) and Blanes $\left(41^{\circ} 41^{\prime} \mathrm{N} 2^{\circ} 48^{\prime} \mathrm{E}\right)$. Total DNA was extracted and amplified using the REDExtract-NAmp Tissue PCR Kit (Sigma Aldrich). Forward primers were labeled with a fluorescent dye (Table 1). Samples were amplified on a PCR System 9700 (Applied Biosystems) with an initial 2 min denaturation step at $95^{\circ} \mathrm{C}$; followed by $35-40$ cycles of $95^{\circ} \mathrm{C}$ for $30 \mathrm{~s}, 52-70^{\circ} \mathrm{C}$ for 
$35 \mathrm{~s}$ (depending on each locus; Table 2) and $72^{\circ} \mathrm{C}$ for $15 \mathrm{~s}$, followed by a 3 min final extension at $72^{\circ} \mathrm{C}$. Amplification products were analyzed on an Applied Biosystems 3730xI Genetic Analyzer at the Scientific-Technical Services of the University of Barcelona. The length and allele scoring of PCR products was estimated relative to the internal size standard GeneScan 600LIZ using the software PEAKSCANNER v1.0 (Applied Biosystems). Linkage disequilibrium, number of alleles per loci and population, observed heterozygosity (Ho), and expected heterozygosity $(\mathrm{He})$ were calculated with GenAlEx (http://biology.anu.edu.au/GenAIEx/Welcome.html) and ARLEQUIN c 3.5.1.2 (Excoffier and Lischer 2010). Genetic diversity (Garza-Williamson (G-W) index) and inbreeding coefficients (FIS) were calculated using ARLEQUIN c 3.5.1.2 and GenPop (http://genepop.curtin.edu.au/). The exact test for departure from Hardy Weinberg Equilibrium (HWE) was also performed with the same software. Narum $(P<0.05)$ corrections of the $p$-values for multiple tests were applied.

\section{Results and Discussion}

Dinucleotide repeats were the most frequent microsatellites followed by tri, tetra and pentanucleotides (Table 1). A total of fourteen polymorphic microsatellite were optimized, including a selection of different microsatellite types (see Tables 1-2) because different microsatellite types are equally valid to assess genetic diversity and populations structure of marine invertebrates (García-Cisneros et al. 2013). No evidence of linkage disequilibrium was detected across all pairwise comparisons. Failed amplifications due to presence of null alleles were detected in two loci of the Caials population (Table 2). Five markers showed HardyWeinberg disequilibrium after Narum corrections but the overall populations were in HardyWeinberg equilibrium (Table 2). Heterozygosity deficit was observed in five loci (3 loci in the Caials population and 2 in the Blanes population; Table 2). The average gene diversity over fourteen loci using the Tajima index was $0.684+/-0.367$ in Caials, and $0.668+/-0.354$ in Blanes. Using the genetic Garza-Williamson index (Garza and Williamson, 2001), it seems that all markers were indicating bottleneck events in both populations (Table 2), but more populations should be sequenced for further confirmation. Further studies applying the microsatellite markers developed herein to additional I. fasciculata populations will allow to understand how the genetic diversity is distributed in this species, and to know its overall 
status, identifying hotspots of genetic diversity, populations affected by large genetic diversity loss and high levels of inbreeding. Information on population genetics of the species is crucial for the assessment of ecological threats and recovery potential following disease episodes and population decimation, and the developing of management strategies when necessary.

\section{Acknowledgements}

Dr. Xavier Turon (CEAB-CSIC) helped with some of the sampling. This study was funded by the Spanish Government project SOLID CTM2010-17755, and the Catalan Government grant 2009SGR-484 for Consolidated Research Groups and Juan de la Cierva contracts to AR and RPP . 
TABLES

Table 1. Total number of microsatellite types found in the genome of $I$. fasciculata.

$\begin{array}{lccc}\text { Type } & \text { Detected } & \text { Attempted } & \text { Successful } \\ \text { Dinucleotide } & 24747 & 14 & 4 \\ \text { Trinucleotide } & 13736 & 14 & 7 \\ \text { Tetranucleotide } & 1348 & 7 & 3 \\ \text { Pentanucleotide } & 278 & 1 & 0 \\ \text { TOTAL } & 40109 & 36 & 14\end{array}$


Table 2. Characteristics of 14 microsatellite markers for I. fasciculata. N: sample size, NA: the number of alleles per locus, HE: expected heterozygosity, HO: observed heterozygosity, FIS: inbreeding coefficient, G-W.: Garza-Williamson index. * and **: Significant deviation from HWE after application of Narum correction $(P<0.05)$. Locus showing significant excess of heterozygotes are shown in bold letters. 


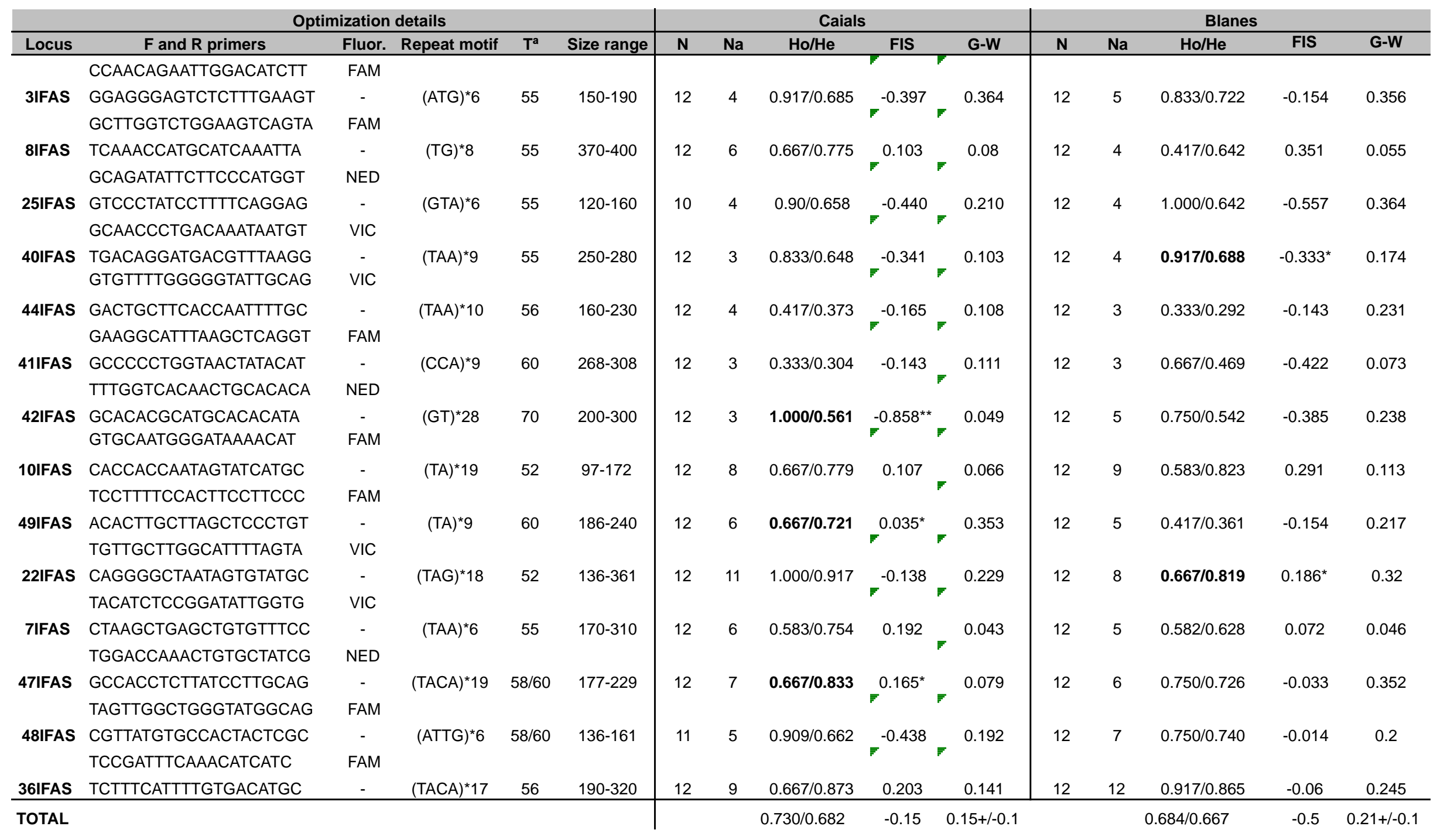




\section{REFERENCES}

-Avila C, Taboada S, Núñez-Pons L (2008) Antarctic marine chemical ecology: what is next?. Mar Ecol 29(1): 1-71

-Cebrián E, Uriz MJ, Garrabou J, Ballesteros E. (2011) Sponge mass mortalities in a warming Mediterranean Sea: Are cyanobacteria-harboring species worse off? PLoS ONE 6(6): e20211

-Excoffier L, Lischer HE. (2010) Arlequin suite ver 3.5: a new series of programs to perform population genetics analyses under Linux and Windows. Mol Ecol Res 10(3): 564-567

-García-Cisneros A, Valero-Jiménez C, Palacín C, Pérez-Portela R. (2013) Characterization of thirty two microsatellite loci for three Atlanto-Mediterranean echinoderm species. Conservation Genet Resour 5: 749-753

-Garza JC, Williamson EG. (2001) Detection of reduction in population size using data from microsatellite loci. Mol Ecol 10(2): 305-318

-Hellberg ME, Burton RS, Neigel JE, Palumbi SR. (2002) Genetic assessment of connectivity among marine populations. Bull Mar Sci 70(1): 273-290

-Hentschel U, Hopke J, Horn M, Friedrich AB, Wagner M, Hacker J, Moore BS. (2002) Molecular evidence for a uniform microbial community in sponges from different oceans. Appl Environ Microbiol 68: 4431-4440

-Maldonado M, Sánchez-Tocino L, Navarro C. (2010) Recurrent disease outbreaks in corneous demosponges of the genus Ircinia: epidemic incidence and defense mechanisms. Mar Biol 157(7): 1577-1590

-Pérez-Portela R, Noyer C, Becerro M. (2013) Genetic structure and diversity of the endangered bath sponge Spongia lamella. Aquatic Conserv: Mar Freshw Ecosyst DOI: $10.1002 /$ aqc. 2423

-Sutherland KP, Porter JW, Torres C. (2004) Disease and immunity in Caribbean and IndoPacific zooxanthellate corals. Mar Ecol Progr Ser 266: 265-272

-Webster NS. (2007) Sponge disease: a global threat? Environ Microbiology 9(6): 1363-1375 